\title{
OPEN Nebulized ivermectin for COVID-19 and other respiratory diseases, a proof of concept, dose-ranging study in rats
}

\author{
Carlos Chaccour ${ }^{1,2,3 凶}$, Gloria Abizanda ${ }^{4,5}$, Ángel Irigoyen-Barrio $0^{6,7}$, Aina Casellas ${ }^{1,8}$, \\ Azucena Aldaz ${ }^{5,6}$, Fernando Martínez-Galán ${ }^{6}$, Felix Hammann ${ }^{9}$ \& Ana Gloria Gil ${ }^{6,7}$
}

Ivermectin is a widely used antiparasitic drug with known efficacy against several single-strain RNA viruses. Recent data shows significant reduction of SARS-CoV-2 replication in vitro by ivermectin concentrations not achievable with safe doses orally. Inhaled therapy has been used with success for other antiparasitics. An ethanol-based ivermectin formulation was administered once to 14 rats using a nebulizer capable of delivering particles with alveolar deposition. Rats were randomly assigned into three target dosing groups, lower dose (80-90 mg/kg), higher dose (110-140 mg/kg) or ethanol vehicle only. A toxicology profile including behavioral and weight monitoring, full blood count, biochemistry, necropsy and histological examination of the lungs was conducted. The pharmacokinetic profile of ivermectin in plasma and lungs was determined in all animals. There were no relevant changes in behavior or body weight. There was a delayed elevation in muscle enzymes compatible with rhabdomyolysis, that was also seen in the control group and has been attributed to the ethanol dose which was up to $11 \mathrm{~g} / \mathrm{kg}$ in some animals. There were no histological anomalies in the lungs of any rat. Male animals received a higher ivermectin dose adjusted by adipose weight and reached higher plasma concentrations than females in the same dosing group (mean $C_{\max } 86.2 \mathrm{ng} / \mathrm{ml}$ vs. $26.2 \mathrm{ng} /$ $\mathrm{ml}$ in the lower dose group and $152 \mathrm{ng} / \mathrm{ml}$ vs. $51.8 \mathrm{ng} / \mathrm{ml}$ in the higher dose group). All subjects had detectable ivermectin concentrations in the lungs at seven days post intervention, up to $524.3 \mathrm{ng} / \mathrm{g}$ for high-dose male and $27.3 \mathrm{ng} / \mathrm{g}$ for low-dose females. nebulized ivermectin can reach pharmacodynamic concentrations in the lung tissue of rats, additional experiments are required to assess the safety of this formulation in larger animals.

As of August 19, 2020, there have been more than 22 million COVID-19 cases causing over 785,000 deaths worldwide. In the absence of a vaccine, numerous efforts are ongoing to develop drug-based strategies to prevent, treat or reduce the transmission of the virus. Data on several drug regimens suggest lack of efficacy for lopinavirritonavir $^{1}$, hydroxychloroquine as prophylaxis ${ }^{2}$ or even harmfulness such as high-dose hydroxychloroquine for prophylaxis $^{3}$ while remdesivir ${ }^{4}$ and dexamethasone ${ }^{5}$ seem to improve patients' outcome.

Ivermectin is a widely used antiparasitic drug with known efficacy against several single-strain RNA viruses including Dengue ${ }^{6}, \mathrm{Zika}^{7}$ and other viruses ${ }^{8}$. The effect on flaviviruses could be explained by a reduction of the viral penetration into the nucleus via an effect on the host's importin alpha/beta $1^{9}$, inhibition of the viral helicase ${ }^{8}$ or yet to be described mechanisms.

Caly et al. showed a significant reduction of SARS-CoV-2 replication after incubating Vero cells, a cell line derived from African Green Monkey kidney epithelial cells, for $48 \mathrm{~h}$ with ivermectin concentrations not readily attainable in vivo ${ }^{10}$. Yet, these findings stirred widespread interest and together with a preprint report of

${ }^{1}$ ISGlobal, Hospital Clínic - Universitat de Barcelona, Rosello 132, 5a 2a, 08036 Barcelona, Spain. ${ }^{2}$ Ifakara Health Institute, 67501 Ifakara, United Republic of Tanzania. ${ }^{3}$ Facultad de Medicina, Universidad de Navarra, 31008 Pamplona, Spain. ${ }^{4}$ Centro de Investigación Médica Aplicada, 31008 Pamplona, Spain. ${ }^{5}$ Clínica Universidad de Navarra, 31008 Pamplona, Spain. ${ }^{6}$ Facultad de Farmacia y Nutrición, Universidad de Navarra, 31008 Pamplona, Spain. ${ }^{7}$ Drug Development Unit Universidad de Navarra, 31008 Pamplona, Spain. ${ }^{8}$ Departament de Fonaments Clínics, Facultat de Medicina, Universitat de Barcelona, Barcelona, Spain. ${ }^{9}$ Department of General Internal Medicine, Clinical Pharmacology and Toxicology, Inselspital, Bern, University Hospital, 3010 Bern, Switzerland. ${ }^{\circledR}$ email: carlos.chaccour@isglobal.org 
potential benefit of a single dose of ivermectin $150 \mathrm{ug} / \mathrm{kg}$ on in-hospital mortality has resulted in extensive use of ivermectin for the treatment or prevention of COVID-19, particularly in Latin-America. There are currently 27 clinical trials registered in clinicaltrials.gov testing ivermectin alone or in combination against COVID-19.

Despite of the mismatch between ivermectin's pharmacokinetics and the $\mathrm{IC}_{50}$ reported by Caly et al., the drug may still prove useful for COVID-19 patients given marginal in vivo effects against dengue in spite of even higher estimated in vitro $\mathrm{IC}_{50}$ values $(>10 \mu \mathrm{M})$ in Vero cells ${ }^{6,11}$, known anti-inflammatory effects ${ }^{12,13}$ and potential additional immunomodulation through an interaction with nicotinic receptors ${ }^{14}$. Another proposed mechanism is the increase of the airway epithelial cell expression of the angiotensin-converting enzyme II (ACE-2) viral entry receptor mediated by activation of nicotinic acetylcholine receptors $(\mathrm{nAChR})^{15}$, primarily the a7 subtype. This would help explain the additional susceptibility of smokers to Covid-19. Inhibition of $\alpha 7$-nAChR may suppress this process, thereby reducing within-host infectivity and transmission. Krause et al. found a comparatively low a7-nAChR IC $_{50}$ for ivermectin of $0.156 \mu \mathrm{M}$, a concentration realistically attainable even on oral drug dosing ${ }^{16}$.

Inhaled therapy could be used to instantaneously reach and maintain effective concentrations in lung tissue. Other authors have previously described successful delivery of antiparasitic drugs using nebulizers that create a particle size capable of reaching alveoli in hospital and community settings ${ }^{17,18}$. We are only aware of a single previous study using nebulized ivermectin, Ji et al. ${ }^{19}$ exposed Sprague-Dawley rats to a known concentration of ivermectin in chamber air and determined the inhaled $\mathrm{LD}_{50}$ at $4 \mathrm{~h}$ to be $3690(2710-5010) \mathrm{mg} / \mathrm{m}^{3}$ and the no adverse events were seen in rats exposed to a concentration of $380 \mathrm{mg} / \mathrm{m}^{3}$ for 21 consecutive days. The study design of Ji et al., however seems intended as an environmental toxicity study, not to guide a therapeutic use of the drug.

Here we report of a pilot rat-model evaluating the feasibility of therapeutic delivery of nebulized ivermectin. The main objectives were to assess the ivermectin pharmacokinetics in plasma and lung tissue as well as safety of this formulation through a comprehensive toxicology profile.

\section{Methods}

Formulation. We unsuccessfully attempted to produce a water soluble-solution by combining surfactants such as polysorbate or co-solvents such as propylene glycol or glycerin. Given solubility issues and that ethanol does not interfere with ivermectin pharmacokinetics ${ }^{20}$, ivermectin powder API was diluted in pure ethanol to reach three different concentrations, $7 \mathrm{mg} / \mathrm{ml}, 10 \mathrm{mg} / \mathrm{ml}$ and $14 \mathrm{mg} / \mathrm{ml}$ and kept in opaque flasks at $5{ }^{\circ} \mathrm{C}$. Stability tests using HPLC conducted one week after dilution showed no changes in the original concentrations. All solutions were used within one week of preparation.

Rats. We used adult, 12-weeks old, Sprague-Dawley rats that were kept in groups of 2-3 subjects of the same sex per cage at the animal research facilities of the University of Navarra. Light, temperature, humidity and feeding conditions followed the local standard operating procedures. Rats in the intervention groups were identified as TM/TF (males/females) plus a correlative number 1-6. Rats in the control group were identified as VCM or VCF for male and female respectively. Cages were identified with the study name and each rat was marked with its individual code in the base of the tail using a non-toxic permanent marker.

Procedures. For the nebulization, we used a Micro Cirrus device (Intersurgical, Berkshire, UK) with a driving oxygen flow of $8 \mathrm{~L} / \mathrm{min}$ which can deliver aerosol particles of $0.5-2 \mu \mathrm{m}$ in diameter resulting in alveolar deposition. A volume of $3 \mathrm{ml}$ of the solutions was used. A 22-mm elbow piece that covered the rats' nose and mouth was used to deliver the cloud (Fig. 1). The oxygen flow was kept until the reservoir was empty at visual inspection for an average nebulizing time of $9 \mathrm{~min}$. The reservoirs were weighed before and after the nebulization to confirm the final weight was the same as the empty one, before the procedure.

The oral lethal concentration $50 \%\left(\mathrm{LC}_{50}\right)$ for rats has been estimated by Merck in $42.8-52.8 \mathrm{mg} / \mathrm{kg}$ for males and $44.3-52.8 \mathrm{mg} / \mathrm{kg}$ for females ${ }^{21}$. The rats for this study were randomly assigned into three groups: (a) lower dose, aiming at twice the lower boundary of the $\mathrm{LC}_{50}$ for their sex; (b) higher dose, aiming at twice the upper boundary of the $\mathrm{LC}_{50}$ for their sex and (c) controls receiving only the ethanol vehicle. The sample was chosen according to usual practice in dose-range finding pilots. Treatment groups included three males and three females each, rats from each sex were housed in separate cages. The first three males received the lower dose, the first three females received the lower dose, the remaining three in each cage were assigned to the missing dosing group and the last rat in each cage remained untreated.

The intervention was administered in dose-groups under anesthesia with ketamine and diazepam 75/5 mg/ $\mathrm{kg}$, intraperitoneal, single dose. Post-administration, the rats were monitored until recovery for 60-90 min on a thermic blanket and then monitored daily using a modified Irwin test ${ }^{22}$ until euthanasia. The weight of all subjects was recorded at baseline, day 3 and at the day of euthanasia. Additionally, a full blood count and a biochemistry toxicology panel including total serum proteins, albumin, aspartate aminotransferase (AST), alanine aminotransferase (ALT), bilirubin, total cholesterol, glucose, creatinine, urea, creatine phosphokinase (CPK)and lactate dehydrogenase $(\mathrm{LDH})$ was performed in one subject per sex/group at euthanasia.

Plasma samples for determination of ivermectin levels were obtained at 1,4 and $24 \mathrm{~h}$ after administration and at the time of euthanasia (days 3, 5 or 7). Blood samples of $0.5 \mathrm{ml}$ were obtained under brief induction anesthesia with inhaled isoflurane $1.5-2 \%$ from the retro orbital plexus, centrifuged and the plasma frozen at $-80^{\circ} \mathrm{C}$ until processing.

A t the end of their corresponding study period (Fig. 2), subjects were euthanized using a $\mathrm{CO}_{2}$ chamber. A macroscopic necropsy was performed in all subjects including external and in situ examination of all organs. The lungs and livers were extracted, measured and weighted separately. One lung and one liver sample from 


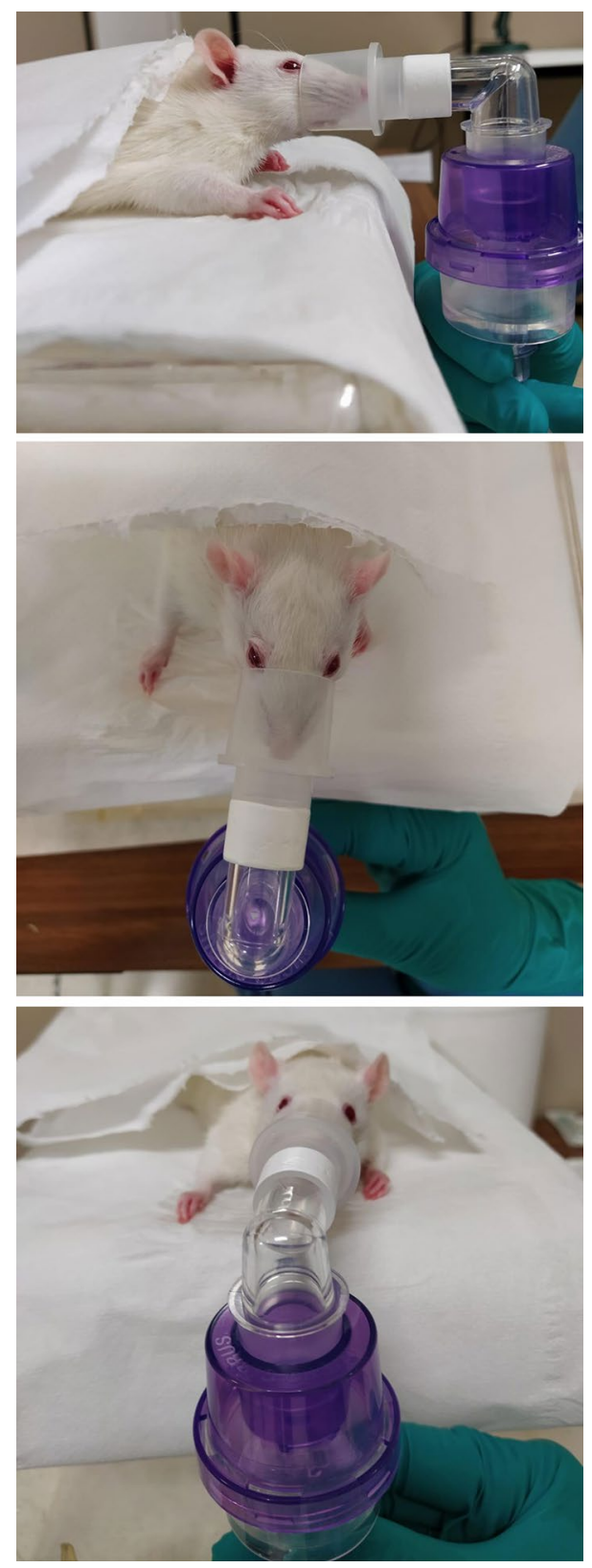

Figure 1. Nebulization procedure.

every subject was preserved in formaldehyde and sent to Patconsult LAB (Barcelona, Spain) for histopathological examination.

Ivermectin levels. Ivermectin plasma levels were determined using a variation of a previously described HPLC-FLD ${ }^{23}$ with a detection limit of $0.1 \mathrm{ng} / \mathrm{ml}$.

Lung tissue $(0.5 \mathrm{mg})$ was homogenized in $1 \mathrm{ml}$ of acetonitrile using an Ultra-turrax homogenizer and the sonicated for $15 \mathrm{~min}, 100 \mathrm{mcl}$ of the homogenized lung were processed in the HPLC-FLD using the plasma methods ${ }^{24}$.

Calculations, data analysis and software. Given that ivermectin deposits in adipose tissue ${ }^{25}$ and that differences in ivermectin's $\mathrm{PK}$ based on body composition have been previously described ${ }^{26}$, the dose per gram of body fat was calculated in all rats. The adipose weight of the rats according to sex was estimated using the formula described by Ferrel and Koong ${ }^{27}$. Comparison of baseline characteristics was done using the Wilcoxon Rank Sum test in Stata 16 Software (StataCorp. 2019. Stata Statistical Software: Release 16. College Station, TX: StataCorp LLC). Body weigh-PK by sex graphs were done in Microsoft Excel (Microsoft corporation, 2018).

Data set checkout and visualizations of pharmacokinetic data were performed in GNU R (R Core Team [2020] R: A language and environment for statistical computing, version 3.6.3, R Foundation for Statistical 


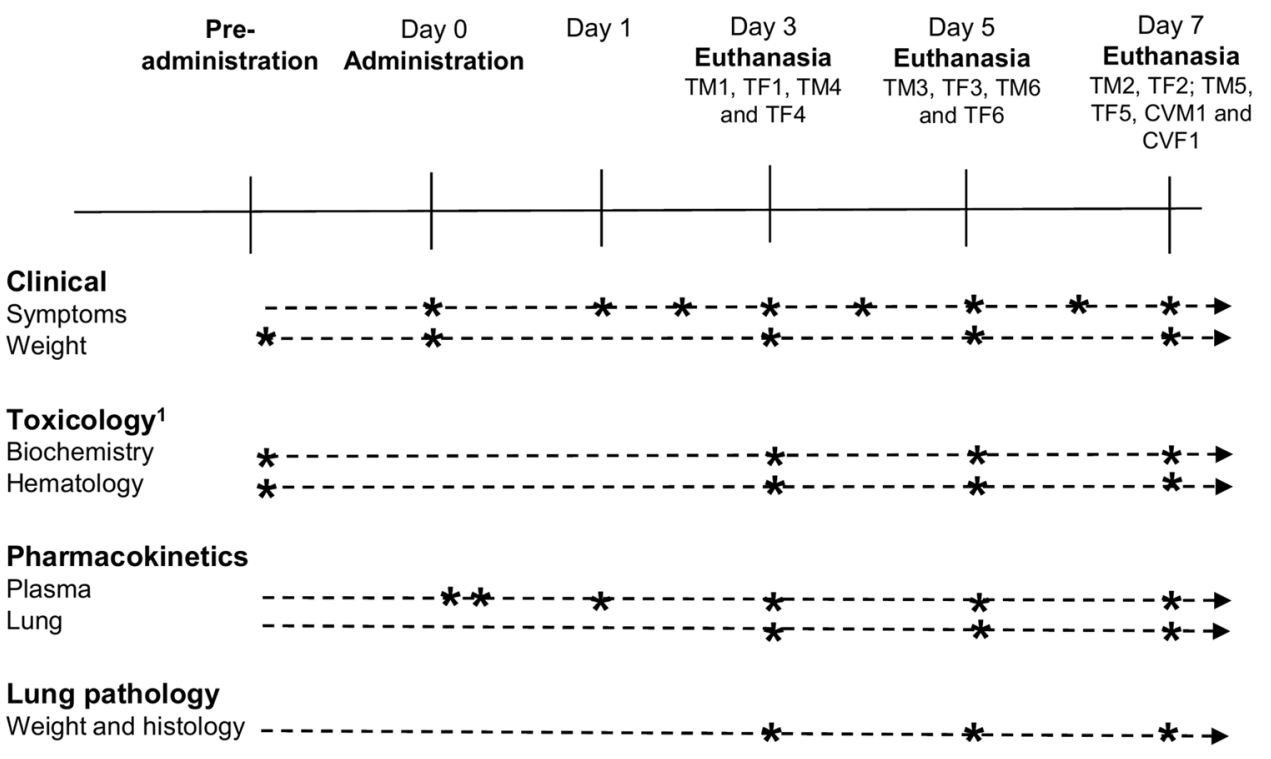

Figure 2. Summary and timeline of study procedures. TM\#/TF\#, CVM and CVF. ${ }^{1}$ One animal per sex and treatment group.

Computing, Vienna, Austria, https://www.R-project.org/). Non-compartmental analysis (NCA) was performed using Pkanalix (Monolix version 2019R2. Antony, France: Lixoft SAS, 2019. https://lixoft.com/products/monol ix/). Peak plasma concentration $\left(C_{\max }\right)$, and time to peak plasma concentration $\left(T_{\max }\right)$ were read directly from the profiles. Terminal elimination half-life $\left(t_{1 / 2}\right)$ was calculated as $t_{1 / 2}=\ln (2) / \lambda_{z}$ after estimating $\lambda_{z}$ from the final two measurements of each profile. The area under the plasma concentration-time curve (AUC) from 0 to $168 \mathrm{~h}$ post-dose $\left(A U C_{0-168 h}\right)$ was calculated using the linear up/log down method. Mean plasma concentrations from 0 to $168 \mathrm{~h}$ post-dose are given as $C_{a v g ., 0-168 h}$. Lung tissue concentrations were back-calculated from lung densities reported by El-Khatib et al. in Sprague-Dawley female rats aged $15-90$ weeks ${ }^{28}$. At 15 weeks of age, the average lung density was about $0.4 \mathrm{~g} / \mathrm{cm}^{3}$, and we therefore converted $1 \mathrm{~g}$ of lung tissue to a volume of $2.2 \mathrm{ml}$.

Ethics. All procedures were reviewed and approved by the Animal research ethics committee of the University of Navarra (Approval Number E11/20 from CEEA 002/20).

Regulatory compliance. All methods were carried out in accordance with relevant guidelines and regulations.

\section{Results}

Baseline characteristics. The baseline characteristics of the rats in by sex is presented in Table 1. Male rats had an approximate median weight $100 \mathrm{~g}(50 \%)$ higher than females $(p$-value $=0.002)$ and different body composition resulted in females having three times the estimated adipose weight (median 92.9 vs. $29.1 \mathrm{~g}$, $p$-value $=0.002$ ).

Intervention and immediate recovery. The recommended minimal volume to generate nebula with the device used is of three $\mathrm{ml}$, given that our formulation is ethanol/based, this volume set the minimal ethanol dose given with the intervention in $2.3 \mathrm{~g}$ (equivalent to $3 \mathrm{ml}$ ). All animals received the intervention uneventfully and recovered from anesthesia within $90 \mathrm{~min}$. At the time of the first blood sample ( $1 \mathrm{~h}$ after the intervention), they showed slight instability and lethargy which was attributed to the alcohol dose and had recovered fully by the time of the second blood sample, $4 \mathrm{~h}$ after the intervention.

Ivermectin dose. The animals in the lower dose group received a median dose of $89 \mathrm{mg} / \mathrm{kg}$ of ivermectin, ranging $86-98 \mathrm{mg} / \mathrm{kg}$ for males and $88-95 \mathrm{mg} / \mathrm{kg}$ for females which correlates well with the target of twice the lower boundary of the oral $\mathrm{LD}_{50}$. The animals in the higher dose group received a median dose of $121 \mathrm{mg} / \mathrm{kg}$ of ivermectin, ranging $108-116 \mathrm{mg} / \mathrm{kg}$ for males and $126-141 \mathrm{mg} / \mathrm{kg}$ for females which represents 2.0 to 2.2 -fold the upper boundary of the oral $\mathrm{LD}_{50}$ for males and 2.3 to 2.6 -fold the upper boundary of the $\mathrm{LD}_{50}$ for females. However, the significantly different adipose weight resulted in male rats receiving much higher doses of ivermectin per gram of fat than females (3.2 to fourfold in the higher dose group, and 3.9 to 5.7 -fold in the lower dose group), weights and doses of all animals are presented in Table 2.

All rats received $3 \mathrm{ml}(2.3 \mathrm{~g})$ of inhaled ethanol, which resulted in weight-adjusted ethanol doses of $6.1-7.7 \mathrm{~g} /$ $\mathrm{kg}$ for males (Table S18) and 9.4-11.1 g/kg for females (Table S19) which is lower than or overlapping with the oral ethanol $\mathrm{LD}_{50}$ described for rats of a similar age $(10.0-11.2 \mathrm{~g} / \mathrm{kg})^{29}$. 


\begin{tabular}{|l|l|l|l|}
\hline \multirow{2}{*}{ Variable } & Sex & \multirow{2}{*}{ Total } \\
\cline { 2 - 3 } & Male & Female & $277.55(237-346.9)[14]$ \\
\hline Baseline weight $(\mathrm{g})^{\mathrm{a}}$ & $346.9(331.5-372.5)[7]$ & $237(218.8-249.5)[7]$ & $25.3(29.1-92.9)[14]$ \\
\hline Fat weight $(\mathrm{g})^{\mathrm{a}}$ & $29.1(27.5-31.8)[7]$ & $92.9(81.6-101.1)[7]$ & 55.3 \\
\hline Dosage & \multicolumn{3}{|l}{} \\
\hline Dose $(\mathrm{mg})^{\mathrm{b}}$ & $1(14 \%)$ & $1(14 \%)$ & $2(14 \%)$ \\
\hline None & $3(43 \%)$ & $3(43 \%)$ & $6(43 \%)$ \\
\hline Lower dose & $3(43 \%)$ & $3(43 \%)$ & $6(43 \%)$ \\
\hline Higher dose & $98.7(86.5-112.8)[7]$ & $96.0(83.6-132.5)[7]$ & $97.3(86.5-116.5)[14]$ \\
\hline Dose (mg/Kg) ${ }^{\mathrm{a}}$ & $1.2(1.0-1.3)[7]$ & $0.3(0.2-0.3)[7]$ & $0.4(0.2-1.2)[14]$ \\
\hline Dose per gram of fat ${ }^{\mathrm{a}}$ & & &
\end{tabular}

Table 1. Baseline characteristics of the rats in each group. ${ }^{a}$ Median (IQR) [n]. ${ }^{b} \mathrm{n}$ (Column percentage).

\begin{tabular}{|c|c|c|c|c|c|c|c|c|c|c|c|c|c|c|}
\hline Group & Subject & $\begin{array}{l}\text { Baseline } \\
\text { weight (g) }\end{array}$ & $\begin{array}{l}\text { Fat } \\
\text { weight } \\
(\mathrm{g})^{\mathrm{a}}\end{array}$ & $\begin{array}{l}\text { Body fat } \\
(\%)\end{array}$ & $\begin{array}{l}\text { Total } \\
\text { dose } \\
(\mathrm{mg})\end{array}$ & $\begin{array}{l}\text { Dose } \\
(\mathrm{mg} / \mathrm{kg})\end{array}$ & $\begin{array}{l}\text { Dose per } \\
\text { gram of } \\
\text { fat }(\mathrm{mg} / \mathrm{g})\end{array}$ & $\begin{array}{l}\text { Plasma } \\
\text { levels } 1 \text { h } \\
(\mathrm{ng} / \mathrm{ml})\end{array}$ & $\begin{array}{l}\text { Plasma } \\
\text { levels } 4 \mathrm{~h} \\
(\mathrm{ng} / \mathrm{ml})\end{array}$ & \begin{tabular}{|l|} 
Plasma \\
levels \\
$24 \mathrm{~h}(\mathrm{ng} /$ \\
$\mathrm{ml})$
\end{tabular} & $\begin{array}{l}\text { Plasma } \\
\text { levels } \\
72 \mathrm{~h}(\mathrm{ng} / \\
\mathrm{ml})\end{array}$ & $\begin{array}{l}\text { Plasma } \\
\text { levels } \\
140 \mathrm{~h} \text { (ng/ } \\
\mathrm{ml})\end{array}$ & \begin{tabular}{|l|} 
Plasma \\
levels \\
$168 \mathrm{~h}(\mathrm{ng} /$ \\
$\mathrm{ml})$
\end{tabular} & $\begin{array}{l}\text { Lung } \\
\text { levels } \\
\text { (ng/g) } \\
\text { (time) }\end{array}$ \\
\hline \multirow{3}{*}{$\begin{array}{l}\text { Lower } \\
\text { dose } \\
\text { males }\end{array}$} & TM1 & 303.9 & 24.69 & 8 & 30 & 98.7 & 1.2 & 55.0 & 29.1 & 81.8 & 74.6 & - & - & $\begin{array}{l}75.6 \\
{[72 \mathrm{~h}]}\end{array}$ \\
\hline & TM2 & 333.2 & 27.71 & 8 & 30 & 90.0 & 1.1 & 26.1 & 29.8 & 96.7 & - & - & 25.9 & $\begin{array}{l}110.6 \\
{[168 \mathrm{~h}]}\end{array}$ \\
\hline & TM3 & 346.9 & 29.12 & 8 & 30 & 86.5 & 1.0 & 36.4 & 48.3 & 80.0 & - & 38.2 & - & $\begin{array}{l}141.2 \\
{[140 \mathrm{~h}]} \\
\end{array}$ \\
\hline \multirow{3}{*}{$\begin{array}{l}\text { Higher } \\
\text { dose } \\
\text { males }\end{array}$} & TM4 & 386.9 & 33.24 & 9 & 42 & 108.6 & 1.3 & 35.9 & 44.2 & 142.9 & 63.4 & - & - & $\begin{array}{l}592.9 \\
{[72 \mathrm{~h}]} \\
\end{array}$ \\
\hline & TM5 & 360.6 & 30.53 & 8 & 42 & 116.5 & 1.4 & 52.5 & 39.6 & 186.7 & - & - & 56.0 & $\begin{array}{l}524.3 \\
{[168 \mathrm{~h}]}\end{array}$ \\
\hline & TM6 & 372.5 & 31.76 & 9 & 42 & 112.8 & 1.3 & 52.4 & 39.9 & 126.4 & - & 58.5 & - & $\begin{array}{l}446.8 \\
{[140 \mathrm{~h}]}\end{array}$ \\
\hline \multirow{3}{*}{$\begin{array}{l}\text { Higher } \\
\text { dose } \\
\text { females }\end{array}$} & $\mathrm{TF} 1$ & 211.6 & 77.35 & 37 & 30 & 141.8 & 0.4 & 9.8 & 9.9 & 33.6 & 15.0 & - & - & $\begin{array}{l}339.2 \\
{[72 \mathrm{~h}]} \\
\end{array}$ \\
\hline & $\mathrm{TF} 2$ & 226.4 & 86.24 & 38 & 30 & 132.5 & 0.3 & 63.4 & 10.9 & 22.8 & - & - & 13.2 & $\begin{array}{l}94.7 \\
{[168 \mathrm{~h}]}\end{array}$ \\
\hline & TF3 & 237 & 92.91 & 39 & 30 & 126.6 & 0.3 & 11.2 & 8.4 & 58.6 & - & 13.4 & - & $\begin{array}{l}170.6 \\
{[140 \mathrm{~h}]} \\
\end{array}$ \\
\hline \multirow{3}{*}{$\begin{array}{l}\text { Lower } \\
\text { dose } \\
\text { females }\end{array}$} & TF4 & 218.8 & 81.61 & 37 & 21 & 96.0 & 0.3 & 11.4 & 10.5 & 27.4 & 6.6 & - & - & $250[72 \mathrm{~h}]$ \\
\hline & TF5 & 251.2 & 102.23 & 41 & 21 & 83.6 & 0.2 & 40.9 & 8.1 & 20.7 & - & - & 6.7 & $\begin{array}{l}27.3 \\
{[168 \mathrm{~h}]} \\
\end{array}$ \\
\hline & TF6 & 238.4 & 93.81 & 39 & 21 & 88.1 & 0.2 & 9.8 & 9.5 & 10.3 & - & 6.9 & - & $\begin{array}{l}13.8 \\
{[140 \mathrm{~h}]} \\
\end{array}$ \\
\hline $\begin{array}{l}\text { Control } \\
(\mathrm{m})\end{array}$ & CVM1 & 331.5 & 27.54 & 8 & 0 & $* *$ & $* *$ & $* *$ & $* *$ & $* *$ & $* *$ & $* *$ & $* *$ & ${ }^{*}[168 \mathrm{~h}]$ \\
\hline $\begin{array}{l}\text { Control } \\
\text { (f) }\end{array}$ & CVF1 & 249.5 & 101.09 & 41 & 0 & $* *$ & $* *$ & $* *$ & $* *$ & $* *$ & $* *$ & $* *$ & $* *$ & ${ }^{* *}[168 \mathrm{~h}]$ \\
\hline
\end{tabular}

Table 2. Weight, body composition, doses, plasma and lung levels of all rats. ${ }^{\star *}$ Below quantification limit. ${ }^{a}$ Ferrel and Koong method.

Behavior, symptoms and weight. All animals had a normal behavior and central nervous system assessment throughout the study according to the modified Irwin procedure (Tables S3-S17).

All animals had a normal weight for their age at baseline, except for one male (TM1) who was $17 \mathrm{~g} \mathrm{(5 \% )} \mathrm{below}$ the lower limit of the normality for 12 weeks $(321 \mathrm{~g})$.

All males except one in the lower dose group had lost weight at day three post intervention, ranging from 2 to $4.2 \%$ of their baseline weight. The control male, nebulized with ethanol vehicle only, lost $3.5 \%$ of its baseline weight by day three. All males except one in the higher dose group that lost further $0.6 \%$, had started to gain weight or recovered their baseline value at the time of euthanasia (Table S18). All females except two (one in the lower dose group and one in the higher dose group) had lost weight at day three post intervention, ranging from 0.4 to $3.4 \%$ of their baseline weight. The control female lost $0.4 \%$ of its baseline weight by day three. All females had started to gain weight or recovered their baseline value at the time of euthanasia (Table S19).

Toxicology labs. Male rats had no significant hematological changes regardless of ivermectin dose group or ethanol dose adjusted by weight (Table S20). All but two female rats had a slight anemia with hemoglobin 


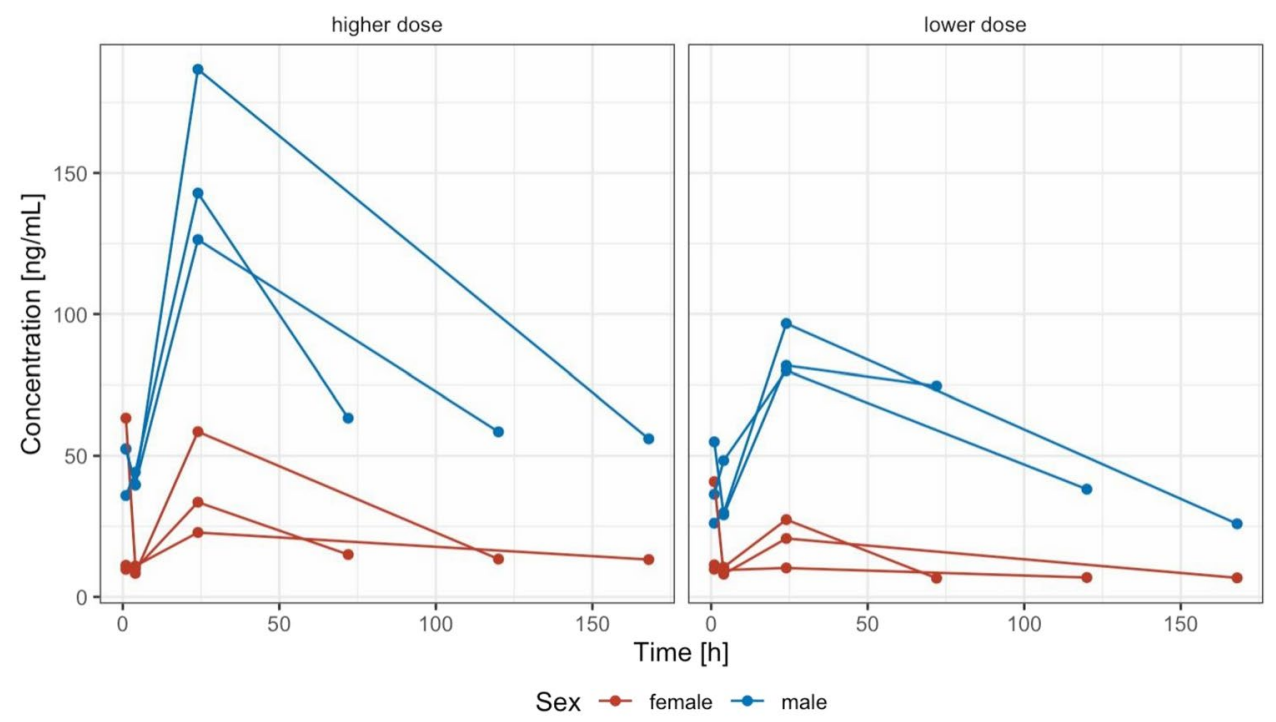

Figure 3. Individual plasma concentration-time curves stratified by sex and dose administered (lower dose $=84-98 \mathrm{mg} / \mathrm{kg}$, higher dose 106-140 mg/kg).

levels 0.1 to $1.7 \mathrm{~g} / \mathrm{dL}$ below the minimum normal value. Additionally, all females had total red blood cells below the normal limit (median $0.8 \times 10^{6} / \mathrm{ul}$ ) and slightly increased mean corpuscular values (median $3.5 \mathrm{fl}$ above the upper normal limit) (Table S21).

Animals in both groups presented a delayed increase (two to threefold the upper level of normality) in creatine kinase $(\mathrm{CPK})$ and lactate dehydrogenase $(\mathrm{LDH})$, this effect was seen earlier in females (all euthanized after $140 \mathrm{~h}$ post administration) than in males (only those euthanized at $168 \mathrm{~h}$ ). Except for one female in the higher ivermectin dose which had AST/ALT values 1.5-fold the upper limit, liver enzymes and bilirubin were normal or below the lower limit in all rats. Two males and all but one female had slightly increased creatinine values. All blood biochemistry results are presented in Supplementary Tables S1 and S2 for males and females respectively.

Necropsy. One male in the higher dose group (TM6) had a patchy pattern in both lungs (Figure S1). There were no macroscopic findings in the thoracic or abdominal organs of any other subject. The absolute and relative-to-body weights of lungs and livers from all subjects where within normal values (Tables S22 and S23). There were no pathologic changes in the histology of liver and lungs samples examined, including the lung sample from the male rat with a macroscopic patchy pattern (Figure S2).

Pharmacokinetics. Individual plasma profiles by dose group and sex are shown in Fig. 3. Secondary pharmacokinetic parameters in plasma are given in Table 3. Concentrations in lung tissue remained detectable in all animals at time of necropsy (72-168 h, Table 2, Fig. 4).

The relationship between the ivermectin dose per gram of fat and the plasma concentrations at 1,4 and $24 \mathrm{~h}$ is shown in Fig. 5.

\section{Discussion}

Dose and body composition. Although the total and weight-adjusted ivermectin doses were comparable between males and females in both dose groups, the higher estimated adipose weight of female rats resulted in a 3 to fourfold dose of ivermectin per gram of fat. Ivermectin accumulates in adipose tissue ${ }^{25}$, this deep compartment affects systemic concentrations of the drug in subjects with different body composition and sex-based differences have been well described before ${ }^{26,30}$. In this experiment there was a direct relationship between the dose per gram of fat and the plasma levels reached at 1, 4 and $24 \mathrm{~h}$. Nebulized ivermectin reached a $\mathrm{C}_{\max }$ twice as high and had an AUC 4 to sixfold higher in male rats regardless of the dosing group. There was also a tendency for lung levels of male rats to be higher regardless of the dosing group.

Toxicology. The hematological changes observed in most female rats, regardless of dosing group, (mild macrocytic anemia and reduced total RBC) are already present in animals euthanized $72 \mathrm{~h}$ after the intervention and could either precede the intervention or be the consequence of the proportionally larger blood loss due sampling in this group. The elevated CPK and LDH observed 5-7 days after the intervention seem to be of muscular origin given normal values of bilirubin and liver enzymes in all rats; we hypothesize these changes are in relationship with the high ethanol dose received (up to $11 \mathrm{~g} / \mathrm{kg}$ of ethanol which is the equivalent of one standard alcohol unit per kg or weight) since they are also present in the control animals that did not receive any ivermectin. Non-traumatic rhabdomyolysis has been reported before in relationship with acute alcohol intoxication ${ }^{31}$ and this is compatible with the slight increase in creatinine values seen in most animals. Alcohol intoxication 


\begin{tabular}{|c|c|c|c|c|c|c|c|c|}
\hline \multirow[b]{2}{*}{ Dose group } & \multirow[b]{2}{*}{ Sex } & \multirow[b]{2}{*}{ Units } & Cmax & $\operatorname{Tmax}(a)$ & Clast & Cavg 0-168 h & $t 1 / 2$ & AUC 0-168 h \\
\hline & & & $(\mathbf{n g} / \mathrm{mL})$ & (h) & $(\mathrm{ng} / \mathrm{mL})$ & $(\mathrm{ng} / \mathrm{mL})$ & (h) & $\left(\mathbf{n g} \mathbf{g}^{\star} \mathbf{h} / \mathbf{m L}\right)$ \\
\hline \multirow{4}{*}{ Lower dose } & \multirow{2}{*}{ Female $(n=3)$} & Mean (SEM) & $26.2(8.9)$ & 24 & $6.7(0.1)$ & $4.7(1)$ & $127.5(52.7)$ & $1610.5(275.1)$ \\
\hline & & Range & \begin{tabular}{|l|}
$10.3-40.9$ \\
\end{tabular} & $1-24$ & $6.6-6.9$ & $3.0-6.4$ & $23.4-193.7$ & $1330.3-2160.7$ \\
\hline & \multirow[b]{2}{*}{ Male $(\mathrm{n}=3)$} & Mean (SEM) & $86.2(5.3)$ & 24 & $46.2(14.6)$ & $17.3(1.5)$ & $175.7(92.9)$ & 9679.6 (958.9) \\
\hline & & Range & $80.0-96.7$ & $24-24$ & $25.9-74.6$ & $14.9-20.0$ & $75.8-361.3$ & \begin{tabular}{|l|}
$8387.0-$ \\
$11,552.8$ \\
\end{tabular} \\
\hline \multirow{4}{*}{ Higher dose } & \multirow{2}{*}{ Female $(\mathrm{n}=3)$} & Mean (SEM) & $51.8(9.2)$ & 24 & $13.9(0.6)$ & $7.5(1.0)$ & $370.8(327.6)$ & $3128.2(526.2)$ \\
\hline & & \begin{tabular}{|l|} 
Range \\
\end{tabular} & 33.6-63.4 & $1-24$ & $13.2-15.0$ & $5.7-9.2$ & $41.3-1026.0$ & $2291.6-4099.3$ \\
\hline & \multirow{2}{*}{ Male $(\mathrm{n}=3)$} & Mean (SEM) & $152.0(18.0)$ & 24 & $59.3(2.2)$ & $25.0(1.5)$ & $70.1(14.6)$ & $\begin{array}{l}13,461.7 \\
(2447.9)\end{array}$ \\
\hline & & Range & $126.4-186.7$ & $24-24$ & $56.0-63.4$ & $23.1-27.9$ & $40.9-86.4$ & $\begin{array}{l}9707.4- \\
18,060.1\end{array}$ \\
\hline
\end{tabular}

Table 3. Secondary pharmacokinetic parameters derived from non-compartmental analysis of plasma concentration-time profiles. AUC $0-168 \mathrm{~h}$, area under the plasma concentration-time curve from time zero to $168 \mathrm{~h} ; \mathrm{C}_{\text {avg }} 0-168 \mathrm{~h}$, mean plasma concentration from 0 to $168 \mathrm{~h}$, Clast, last observed plasma concentration, $\mathrm{C}_{\max }$, maximum plasma concentration; $\mathrm{t} 1 / 2$, terminal plasma elimination half-life; SEM, standard error of the mean; $\mathrm{T}_{\max }$, time to reach $\mathrm{C}_{\max }$ (a) media.

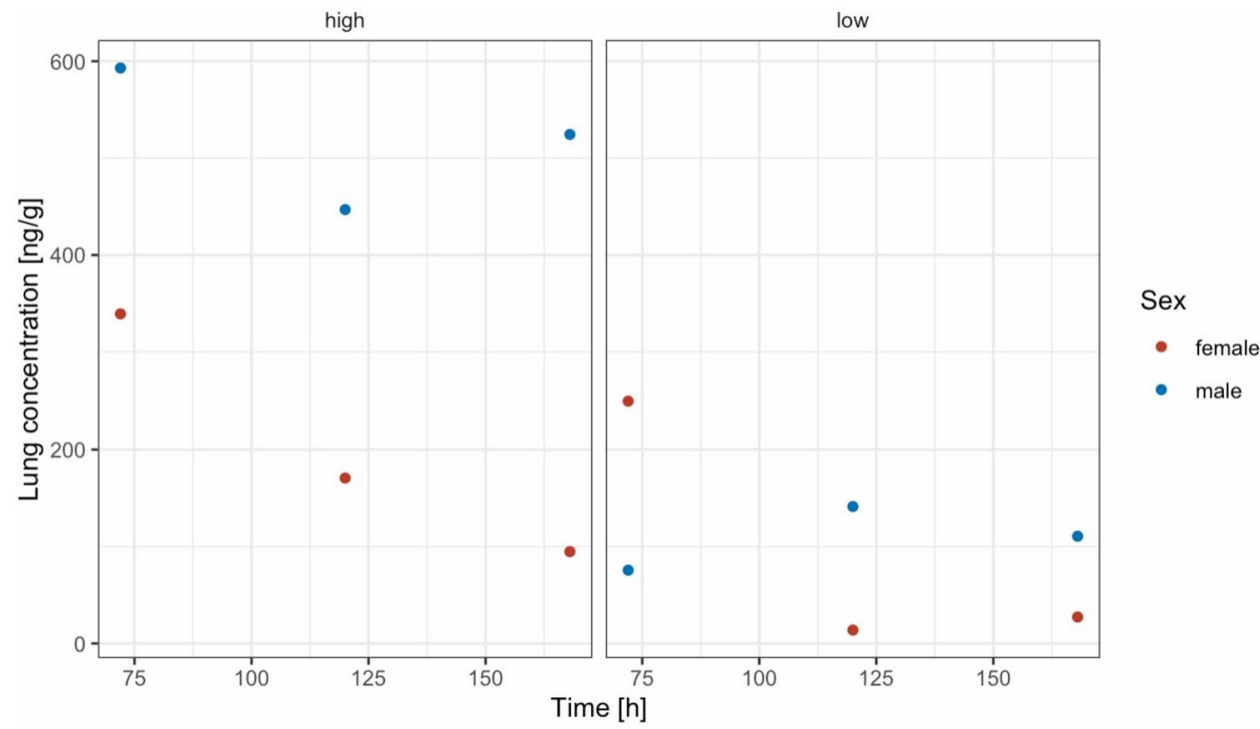

Figure 4. Lung concentrations at necropsy for all animals stratified by dose administered and sex (lower dose $=84-98 \mathrm{mg} / \mathrm{kg}$, higher dose $106-140 \mathrm{mg} / \mathrm{kg}$ ).

is also compatible with the described initial weight loss and posterior recovery. The anesthesia used during the intervention and for the PK sampling could have played a role in the CPK/LDH elevation but isoflurane is not known to increase $\mathrm{LDH}^{32}$ and ketamine-induced elevations are generally of smaller magnitude ${ }^{33}$. The ethanol dose that a $70-\mathrm{kg}$ human adult would receive with a nebulized $3 \mathrm{ml}$ solution would be $2.36 \mathrm{~g}$ (the equivalent of $1 / 5$ of one standard alcohol unit) or 300 -fold less than the dose received by the rats in this study. In any case, care must be taken as recreational use of inhaled ethanol can be used in binge-like patterns, even if immediate safety concerns are relatively minor ${ }^{34}$.

Pharmacokinetics. Upon visual inspection most concentration-time curves show a biphasic profile. We attribute this to double absorption first through inhalation (fast uptake) and then oral absorption (slower uptake) of swallowed drug. It is notable that the second peak is higher than the first, indicating that the majority of drug was swallowed. This is a common phenomenon in nebulized vehicles where subjects are not skilled at inhalation or unable to comply with instructions. We therefore assume that considerably higher lung exposure could be achieved in intubated animals. Nebulized administration of ivermectin to human volunteers would presumable also allow for better deposition of the drug in the respiratory tract and lower circulating levels.

We attempted to characterize the pharmacokinetic behavior and fractions absorbed via both ways using a population-based approach. As the initial uptake in the lungs occurs very early in the profiles where sampling was 


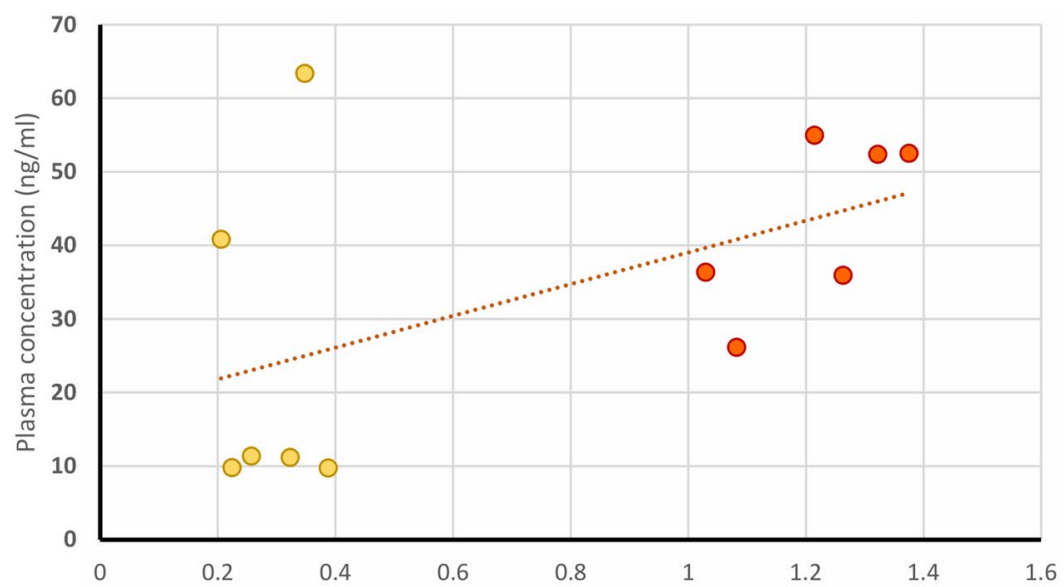

1 hour

oMales

oFemales

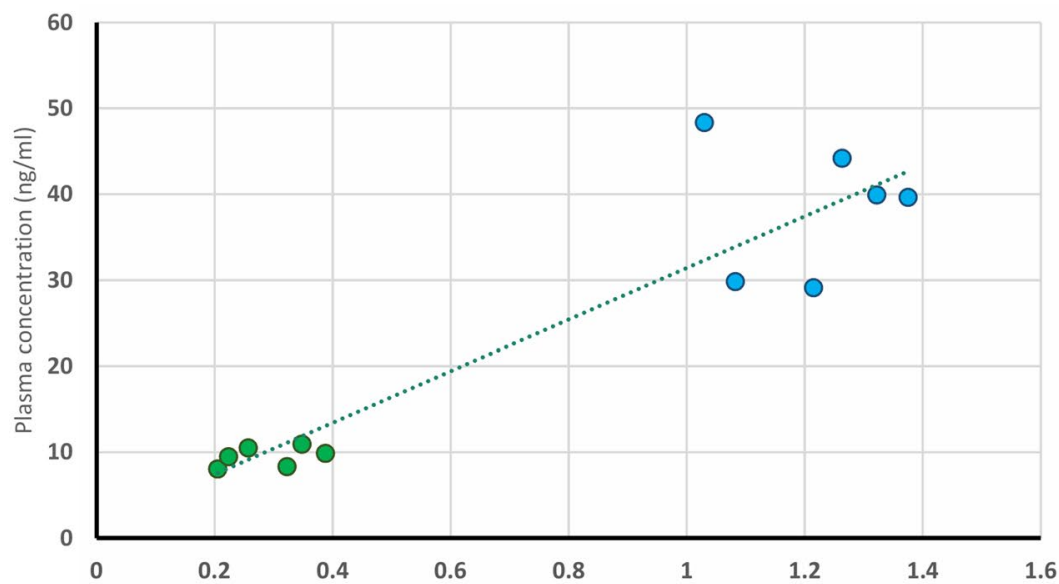

4 hours

oMales

OFemales

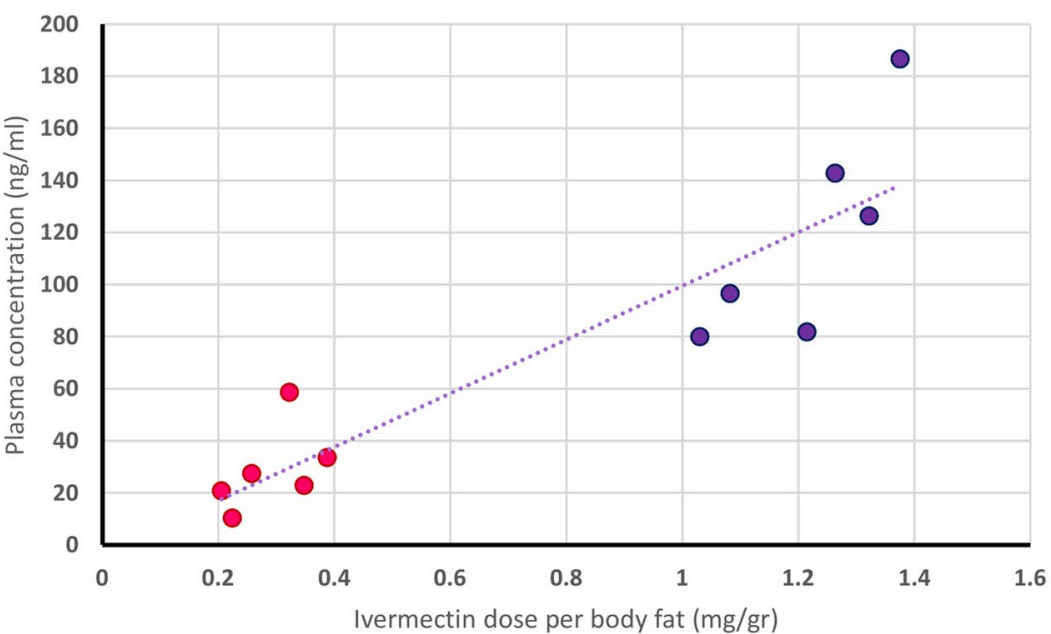

24 hours

OMales

-Females

Figure 5. Relationship between dose per gram of fat and ivermectin plasma levels at 1,4 and $24 \mathrm{~h}$ after nebulization in rats.

not frequent, we were unable to construct robust models. Future trials could overcome this by more intensively sampling subjects during the first hours post-dose.

Achieving pharmacodynamic targets. The highest observed plasma concentration was $186.7 \mathrm{ng} / \mathrm{mL}$ which corresponds to $0.21 \mu \mathrm{M} / \mathrm{L}$ and is clearly below the $\mathrm{IC}_{50} \sim 2 \mu \mathrm{M}$ reported by Caly et al. ${ }^{10}$. Previous experience in Dengue virus infection with the translation of in vitro results to effectivity in human subjects has shown that Vero cell results should be interpreted qualitatively, not quantitatively. The actual $\mathrm{IC}_{50}$ in humans and even respiratory epithelial cells may be quite different. 
Concentrations are, however, above the nicotinergic acetylcholine receptor ( $\mathrm{nAChR}$ ) $\mathrm{IC}_{50}$ for ivermectin as estimated by Krause et al. ${ }^{16}$. Lung tissue concentrations in male rats in the high-dose arm were well above this concentration after 72-168 h (Figure S3). Without a more thorough understanding of the absorption process, it is difficult to extrapolate what concentrations could be achieved with proper inhalation technique. It is, however, safe to say that ivermectin lung delivery with nebulized formulations can maintain detectable concentrations for 7 days.

The delivery method investigated here is not directly translatable to human clinical trials. Safety has to be demonstrated not only for ivermectin but also the ethanol vehicle. Our experience in man with ivermectin is with oral formulations only (sporadic case reports of compassionate use of veterinary parenteral products not considered). Oral bioavailability is not known, and it is conceivable that absorption via lung tissue is more complete as there is no first-pass effect compared to oral administration. We may therefore see higher, possibly toxic, systemic exposure on inhalation. Preliminary safety and dose-finding studies should be conducted with a second arm with oral dosing of the same amounts to quantify relative bioavailability.

Ivermectin has shown in vitro and in vivo effects against other flaviviridae. How well the respective modes of action translate to SARS-CoV-2 is under investigation. Until we have more appropriate in vitro results for key steps such as viral entry via ACE2 receptors or nicotinic receptors, or viral replication, drug regimen design will be difficult.

Other potential disease targets. Ivermectin is efficacious against several helminths of human and veterinary importance that have a pulmonary phase during their lifecycle ${ }^{35}$. There are raising concerns about emerging anti-helminthic resistance and its potential impact on human health and livelihood ${ }^{36}$, targeting these parasites while they are in the lungs (some of them with extended lung residence periods) with much higher concentrations than usually available after oral administration provides a potential answer to these concerns.

In human medicine, this could impact individual care of patients with Soil transmitted helminths, including those with disseminated strongyloidiasis ${ }^{37}$ in whom oral administration of the ivermectin is not always successful ${ }^{38,39}$.

Another potential application is on the treatment or prevention of helminths currently considered not susceptible to ivermectin like Schistosoma mansoni, which expresses a variant of ivermectin's primary target, the glutamate-gated chloride channels, that is only susceptible to a concentration of $1 \mu \mathrm{M}$, which is not readily attainable with oral doses but can be reached in the lung with a nebulized formulation.

Additionally, ivermectin's anti-inflammatory properties may serve as primary or adjuvant therapy for respiratory diseases with an inflammatory component caused by chemical agents or pathogens ${ }^{35,40}$ as well as local and metastatic cancer ${ }^{41}$.

Limitations of this study. This proof-of-concept study could be considered a pilot given the reduced number of animals used, other limitations include that a single measure from the lung concentration was taken at any given point which prevents the assessment of whether there is differential deposit within an individual lung or that there was no concurrent control for the toxicology of rats euthanized at 72 or $140 \mathrm{~h}$. Additionally, the formulation was administered by nose and mouth exposure, hence, the lung levels achieved may not reflect those potentially achieved in a human with active inhalation.

We acknowledge that an ethanol-based formulation administered with a system that requires a high flow of oxygen was appropriate for proving the concept but not for scale up, further investment into formulation development would be needed to pursue this route of administration for any potential indication.

Next steps. The finding that ivermectin concentrations with potential for pharmacodynamic effect were measured in the lungs seven days after inhaled therapy warrant additional research on the potential use of nebulized ivermectin for susceptible respiratory diseases including COVID-19. The immediate next step is the conduction of an extended animal model in rodent and non-rodent species to collect the additional safety data required for a first administration in humans and potentially, the use of animal models of infection to assess the efficacy of this therapy against relevant pathogens including SARS-CoV-2, helminths and possibly inflammatory as well as neoplastic diseases proper of the lung tissue.

\section{Conclusion}

This study provides evidence that ivermectin can be delivered in high concentrations to rat lungs by nebulization, but this warrants additional research to determine safety and efficacy, not direct extrapolation to humans via compassionate use or accelerated approval.

\section{Data availability}

All study data is contained within this manuscript and the supplementary material.

Received: 13 July 2020; Accepted: 25 September 2020

Published online: 13 October 2020

\section{References}

1. Yang, P., Tekwani, S. \& Martin, G. S. In COVID-19, adding lopinavir-ritonavir to usual care did not shorten time to clinical improvement. Ann. Intern. Med. 172, JC63. https://doi.org/10.7326/ACPJ202006160-063 (2020).

2. Boulware, D. R. et al. A randomized trial of hydroxychloroquine as postexposure prophylaxis for covid-19. N. Engl. J. Med. https ://doi.org/10.1056/NEJMoa2016638 (2020). 
3. Borba, M. G. S. et al. Effect of high vs low doses of chloroquine diphosphate as adjunctive therapy for patients hospitalized with severe acute respiratory syndrome coronavirus 2 (SARS-CoV-2) infection: a randomized clinical trial. JAMA Netw. Open 3, e208857. https://doi.org/10.1001/jamanetworkopen.2020.8857 (2020).

4. Beigel, J. H. et al. Remdesivir for the treatment of covid-19-preliminary report. N. Engl. J. Med. https://doi.org/10.1056/NEJMo a2007764 (2020).

5. Horby, P. et al. Effect of dexamethasone in hospitalized patients with COVID-19: preliminary report. medRxiv https://doi. org $/ 10.1101 / 2020.06 .22 .20137273(2020)$

6. Wagstaff, K. M., Sivakumaran, H., Heaton, S. M., Harrich, D. \& Jans, D. A. Ivermectin is a specific inhibitor of importin alpha/betamediated nuclear import able to inhibit replication of HIV-1 and dengue virus. Biochem. J. 443, 851-856. https://doi.org/10.1042/ BJ20120150 (2012).

7. Barrows, N. J. et al. A screen of FDA-approved drugs for inhibitors of Zika virus infection. Cell Host Microbe 20, 259-270. https ://doi.org/10.1016/j.chom.2016.07.004 (2016).

8. Mastrangelo, E. et al. Ivermectin is a potent inhibitor of flavivirus replication specifically targeting NS3 helicase activity: new prospects for an old drug. J. Antimicrob. Chemother. 67, 1884-1894. https://doi.org/10.1093/jac/dks147 (2012).

9. Yang, S. N. Y. et al. The broad spectrum antiviral ivermectin targets the host nuclear transport importin alpha/betal heterodimer. Antiviral Res. https://doi.org/10.1016/j.antiviral.2020.104760 (2020).

10. Caly, L., Druce, J., Catton, M., Jans, D. \& Wagstaff, K. M. The FDA-approved drug ivermectin inhibits the replication of SARSCoV-2 in vitro. Antivir. Res. https://doi.org/10.1016/j.antiviral.2020.104787 (2020) (in Press, Journal Pre-proof).

11. Chaccour, C., Hammann, F., Ramon-Garcia, S. \& Rabinovich, N. R. Ivermectin and novel coronavirus disease (COVID-19): keeping rigor in times of urgency. Am. J. Trop. Med. Hyg. https://doi.org/10.4269/ajtmh.20-0271 (2020).

12. Zhang, X. et al. Ivermectin inhibits LPS-induced production of inflammatory cytokines and improves LPS-induced survival in mice. Inflamm. Res. 57, 524-529. https://doi.org/10.1007/s00011-008-8007-8 (2008).

13. Ci, X. et al. Avermectin exerts anti-inflammatory effect by downregulating the nuclear transcription factor kappa-B and mitogenactivated protein kinase activation pathway. Fundam. Clin. Pharmacol. 23, 449-455. https://doi.org/10.1111/j.1472-8206.2009.00684 .x (2009).

14. Changeux, J., Amoura, Z., Rey, F. \& Miyara, M. A nicotinic hypothesis for Covid-19 with preventive and therapeutic implications. C. R. Biol. https://doi.org/10.5802/crbiol.8 (2020).

15. Russo, P. et al. COVID-19 and smoking: is nicotine the hidden link?. Eur. Respir. J. 55, 2001116. https://doi.org/10.1183/13993 003.01116-2020 (2020).

16. Krause, R. M. et al. Ivermectin: a positive allosteric effector of the alpha7 neuronal nicotinic acetylcholine receptor. Mol. Pharmacol. 53, 283-294. https://doi.org/10.1124/mol.53.2.283 (1998).

17. Montgomery, A. B. et al. Aerosolised pentamidine as sole therapy for Pneumocystis carinii pneumonia in patients with acquired immunodeficiency syndrome. Lancet 2, 480-483. https://doi.org/10.1016/s0140-6736(87)91794-6 (1987).

18. McIvor, R. A., Berger, P., Pack, L. L., Rachlis, A. \& Chan, C. K. An effectiveness community-based clinical trial of Respirgard II and Fisoneb nebulizers for Pneumocystis carinii prophylaxis with aerosol pentamidine in HIV-infected individuals. Toronto Aerosol Pentamidine Study (TAPS) Group. Chest 110, 141-146. https://doi.org/10.1378/chest.110.1.141 (1996).

19. Lei, J. I. et al. Study on the subacute inhalation toxicity of Ivermectin TC in rats. Chin. J. Comp. Med. 26, 70-74 (2016).

20. Homeida, M. M. et al. The lack of influence of food and local alcoholic brew on the blood level of Mectizan((R)) (ivermectin). Acta Trop. 127, 97-100. https://doi.org/10.1016/j.actatropica.2013.03.019 (2013).

21. FDA. Center for drug evaluation and research. Approval package for Mectizan. https://www.accessdata.fda.gov/drugsatfda_docs/ nda/96/050742ap.pdf. Accessed July 2016.

22. Mathiasen, J. R. \& Moser, V. C. The Irwin test and functional observational battery (FOB) for assessing the effects of compounds on behavior, physiology, and safety pharmacology in rodents. Curr. Protoc. Pharmacol. 83, e43. https://doi.org/10.1002/cpph.43 (2018).

23. Eraslan, G. et al. Comparative pharmacokinetics of some injectable preparations containing ivermectin in dogs. Food Chem. Toxicol. 48, 2181-2185. https://doi.org/10.1016/j.fct.2010.05.043 (2010).

24. Lifschitz, A. et al. Comparative distribution of ivermectin and doramectin to parasite location tissues in cattle. Vet. Parasitol. 87, 327-338. https://doi.org/10.1016/s0304-4017(99)00175-2 (2000).

25. Baraka, O. Z. et al. Ivermectin distribution in the plasma and tissues of patients infected with Onchocerca volvulus. Eur. J. Clin. Pharmacol. 50, 407-410 (1996).

26. Ouedraogo, A. L. et al. Efficacy and safety of the mosquitocidal drug ivermectin to prevent malaria transmission after treatment: a double-blind, randomized, clinical trial. Clin. Infect. Dis. 60, 357-365. https://doi.org/10.1093/cid/ciu797 (2015).

27. Ferrell, C. L. \& Koong, K. J. Influence of plane of nutrition on body composition, organ size and energy utilization of SpragueDawley rats. J. Nutr. 116, 2525-2535. https://doi.org/10.1093/jn/116.12.2525 (1986).

28. El-Khatib, E. \& Lehnert, S. Lung density changes observed in vivo in rat lungs after irradiation: variations among and within individual lungs. Int. J. Radiat. Oncol. Biol. Phys. 16, 745-754. https://doi.org/10.1016/0360-3016(89)90494-x (1989).

29. Wiberg, G. S., Trenholm, H. L. \& Coldwell, B. B. Increased ethanol toxicity in old rats: changes in LD50, in vivo and in vitro metabolism, and liver alcohol dehydrogenase activity. Toxicol. Appl. Pharmacol. 16, 718-727. https://doi.org/10.1016/0041-008x(70)90077 $-3(1970)$.

30. Vanapalli, S. R. et al. Orange juice decreases the oral bioavailability of ivermectin in healthy volunteers. Clin. Pharmacol. Ther. 73, P94-P94. https://doi.org/10.1016/S0009-9236(03)90702-8 (2003).

31. Papadatos, S. S. et al. Nontraumatic rhabdomyolysis with short-term alcohol intoxication-a case report. Clin. Case Rep. 3, 769-772. https://doi.org/10.1002/ccr3.326 (2015).

32. Nishiyama, T., Yokoyama, T. \& Hanaoka, K. Liver function after sevoflurane or isoflurane anaesthesia in neurosurgical patients. Can. J. Anaesth. 45, 753-756. https://doi.org/10.1007/BF03012146 (1998).

33. Gil, A. G., Silvan, G., Illera, M. \& Illera, J. C. The effects of anesthesia on the clinical chemistry of New Zealand White rabbits. Contemp. Top. Lab. Anim. Sci. 43, 25-29 (2004)

34. MacLean, R. R., Valentine, G. W., Jatlow, P. I. \& Sofuoglu, M. Inhalation of alcohol vapor: measurement and implications. Alcohol Clin. Exp. Res. 41, 238-250. https://doi.org/10.1111/acer.13291 (2017).

35. Schwartz, C., Hams, E. \& Fallon, P. G. Helminth modulation of lung inflammation. Trends Parasitol. 34, 388-403. https://doi. org/10.1016/j.pt.2017.12.007 (2018).

36. Sutherland, I. A. \& Leathwick, D. M. Anthelmintic resistance in nematode parasites of cattle: a global issue?. Trends Parasitol 27, 176-181. https://doi.org/10.1016/j.pt.2010.11.008 (2011).

37. Chaccour, C. J. \& Del Pozo, J. L. Case 23-2012: a man with abdominal pain and weight loss. N. Engl. J. Med. 367, 1670-1671. https ://doi.org/10.1056/NEJMc1210168\#SA2 (2012).

38. Salluh, J. I. et al. Successful use of parenteral ivermectin in an immunosuppressed patient with disseminated strongyloidiasis and septic shock. Intensive Care Med. 31, 1292 (2005).

39. Pacanowski, J. et al. Subcutaneous ivermectin as a safe salvage therapy in Strongyloides stercoralis hyperinfection syndrome: a case report. Am. J. Trop. Med. Hyg. 73, 122-124 (2005).

40. Zhang, X. et al. Protective effect of abamectin on acute lung injury induced by lipopolysaccharide in mice. Fundam. Clin. Pharmacol. 25, 700-707. https://doi.org/10.1111/j.1472-8206.2010.00896.x (2011). 
41. Melotti, A. et al. The river blindness drug Ivermectin and related macrocyclic lactones inhibit WNT-TCF pathway responses in human cancer. EMBO Mol. Med. 6, 1263-1278. https://doi.org/10.15252/emmm.201404084 (2014).

\section{Acknowledgements}

This study was supported by the University of Navarra with a generous donation from Jeffery and Heart Deal. CCh received salary support from Unitaid through the BOHEMIA Grant to ISGlobal. ISGlobal acknowledges support from the Spanish Ministry of Science and Innovation through the "Centro de Excelencia Severo Ochoa 2019-2023” Program (CEX2018-000806-S), and support from the Generalitat de Catalunya through the CERCA Program.

\section{Author contributions}

Conceptualization: C.Ch., G.A., A.A., F.M.G., A.G.G., Data curation: C.Ch., A.C., F.H., Formal analysis: C.Ch., A.C., F.H., Funding acquisition: C.Ch., A.G.G., Investigation: G.A., A.I.B., F.M.G., A.G.G., Methodology: C.Ch., G.A., A.I.B., A.A., F.H., A.G.G., Supervision: A.G.G., Writing - original draft: C.Ch., A.G.G., F.H., Writing review \& editing: all authors contributed, reviewed and approved the last draft.

\section{Funding}

The funding source had no role on the design, analysis or decision to publish the results of this study.

\section{Competing interests}

The authors declare no competing interests.

\section{Additional information}

Supplementary information is available for this paper at https://doi.org/10.1038/s41598-020-74084-y.

Correspondence and requests for materials should be addressed to C.C.

Reprints and permissions information is available at www.nature.com/reprints.

Publisher's note Springer Nature remains neutral with regard to jurisdictional claims in published maps and institutional affiliations.

(c) (1) Open Access This article is licensed under a Creative Commons Attribution 4.0 International License, which permits use, sharing, adaptation, distribution and reproduction in any medium or format, as long as you give appropriate credit to the original author(s) and the source, provide a link to the Creative Commons licence, and indicate if changes were made. The images or other third party material in this article are included in the article's Creative Commons licence, unless indicated otherwise in a credit line to the material. If material is not included in the article's Creative Commons licence and your intended use is not permitted by statutory regulation or exceeds the permitted use, you will need to obtain permission directly from the copyright holder. To view a copy of this licence, visit http://creativecommons.org/licenses/by/4.0/.

(C) The Author(s) 2020 